\title{
Teleconnections between tropical-extratropical oceans and the daily intensity of extreme rainfall over Argentina
}

\author{
Federico Ariel Robledo, ${ }^{\mathrm{a}, \mathrm{b} *}$ Olga C. Penalba ${ }^{\mathrm{b}}$ and María Laura Bettolli ${ }^{\mathrm{a}, \mathrm{b}}$ \\ ${ }^{a}$ Consejo Nacional de Investigaciones Científicas y Técnicas. FCEN UBA, Buenos Aires, Argentina \\ ${ }^{\mathrm{b}}$ Departamento de Atmósfera y los Océanos. FCEN UBA, Buenos Aires, Argentina
}

\begin{abstract}
A Singular value decomposition (SVD) analysis was performed jointly on the daily intensity of extreme rainfall (DIER) over Argentina and the sea surface temperature (SST) of all the oceans from $17.5^{\circ} \mathrm{N}$ to $90^{\circ} \mathrm{S}$ in order to identify the large-scale variability of the SSTs related to extreme rainfall, in the period 1962-2005. The main objective of the article is to objectively recognize regions of the tropical and subtropical oceans that could be related with the extreme rainfall over Argentina. Spring is the season that is best represented by the first mode, accounting for up to $45 \%$ of the covariance between the DIER and SST. The first SVD mode of spring, summer and autumn presents a pattern of SST relating to the El Niño-Southern Oscillations (ENSO) phenomena with an enhanced DIER in different zones of centre and east of Argentina. In the second SVD mode of spring and summer, the SST patterns show cold conditions in the tropical and subtropical Atlantic and near Indonesia with an enhancement of the DIER in the centre and east of Argentina. These modes show a significant decadal variability. In the third SVD mode of spring and summer, the SST patterns present warm and cold conditions in the Indian Ocean and the centre and western Pacific Ocean (PO) with decreased rainfall in the northern and eastern portion of Argentina, respectively. This mode shows a significant period of temporal variability of around 14 years. The third mode of autumn presents warm conditions in the tropical Atlantic and the southwest PO with a low DIER in the centre and east of Argentina. This mode also presents temporal variability of around 14 years. The correlation between each mode derived from analysis of SVD and climate indices related with SST were computed. Copyright $\subset 2012$ Royal Meteorological Society
\end{abstract}

KEY WORDS teleconnections; tropical oceans; daily precipitation; Argentina

Received 30 August 2011; Revised 23 February 2012; Accepted 25 February 2012

\section{Introduction}

The impact of climate variability on the environmental and economic activities mainly depends on changes in the frequency of extreme events. Relatively few studies on the regional variability of climatic extremes can be found in the literature compared with the number of studies on changes in climatic means. Relatively small changes in the mean could produce substantial changes in the frequency of extreme events (Karl et al., 1984; Mearns et al., 1984). The impact of climate change on climate variability will be particularly felt through changes in extreme events because they will stress or exceed our current adaptations.

The study of rainfall in southern South America serves as an important tool for the sustainable development of the region in several ways. During recent decades, many articles have analysed temporal variability of accumulated precipitation on annual, seasonal or monthly scales in southeastern South America (SESA). Different authors' research presents evidence of an increase in total annual rainfall in different regions in Argentina (Krepper

* Correspondence to: F. A. Robledo, Pab.II 2 piso, Ciudad Universitaria, (1428), Buenos Aires, Argentina. E-mail: frobledo@at.fcen.uba.ar et al., 1989; Castañeda and Barros, 1994; Penalba and Vargas, 1996; Minetti et al., 2003). This increase does not exhibit coherent spatial behaviour. Towards the west of Argentina, many authors observed a 'jump' or discontinuity around the 1950s or 1960s depending on the region; in particular, the increase is more gradual eastward (Minetti and Vargas, 1997; Garcia and Vargas, 1998; Rusticucci and Penalba, 2000; Boulanger et al., 2005; Penalba and Vargas, 2004).

Research on changes in rainfall extremes has increased in recent years, especially since the IPCC first Assessment Report (Houghton et al., 1990) identified a scarcity of such studies. Over central-northeastern Argentina, the annual and extreme precipitation, show an interannual and a decadal variability. (Penalba and Vargas, 2008).

Penalba and Robledo (2010) observed increases in the annual daily extreme rainfall in spatially coherent areas over Argentina. This coherence was more marked in austral summer, autumn and spring, during which the greatest increase occurred in southern Brazil. In winter, the centre-east of Argentina showed negative trends, some of which were significant. Haylock et al. (2006) analysed the spatial covariability between annual indices of rainfall and sea surface temperatures (SSTs) and its temporal variability. They found that the time series of 
the loadings associated to the coupled patterns between El Niño-Southern Oscillations (ENOS) SST and extreme rainfall show similarities with the observed trends of extreme daily rainfall over some southern regions of South America.

The main climate mode of Southern Hemisphere is ENSO, and consists of Rossby wave trains that extend southeast from the tropical Pacific and return to equator in the vicinity of Antarctica through South America (Kidson, 1999). During El Niño, the wave train emanating from the central Pacific anomaly induces a cyclonic circulation in the extratropical region of South America and an anticyclonic anomaly in the tropical region (Grimm et al., 2000). This movement generates an anomalous convergence of moisture transport in the SESA increasing precipitation and divergence in the transport of moisture in the South Atlantic convergence zone (SACZ). In addition, the variability of precipitation anomaly dipole is related to SST anomalies in the Tropical South Atlantic Ocean (AO). In particular, positive phases of the dipole pattern corresponds to positive anomalies of precipitation over SESA and negative on SACZ, associated with warm SST anomalies in the western tropical AO (Doyle and Barros, 2002).

Grimm and Tedeschi (2009) concluded that southern Brazil exhibited a large increment in the frequency of extreme precipitation during El Niño years. Previous studies identified regional changes in the total rainfall and links with SST and circulation. Studies by Aceituno (1988), Rogers (1988), Ropelewski and Halpert (1987), Diaz et al. (1998) and Montecinos et al. (2000) identified a decrease in rainfall in northeastern Brazil and an increase in southeastern Brazil, northern Argentina, Paraguay and Uruguay associated with El Niño events.

Barros and Silvestri (2002) and Vera et al. (2004) stressed the importance of SST variations in the south central Pacific in modulating the influence of El Niño events during spring over SESA. They found that the influence is larger if the equatorial Pacific SST anomaly has a different sign than the SST anomalies in the south central Pacific.

Antico (2008) found two sets of El Niño events whose impact differed in the monthly precipitation in SESA in autumn: one in which the warming core migrates eastward along the tropical Pacific until April-June of the following year, and another one in which it evolves westward until November-January. The first type is associated with positive precipitation anomalies over SESA during April-June. The second type of event exhibits slightly negative or near-normal precipitation anomalies over the same region.

However, in certain years, the SST in the tropical Pacific is not a typical canonical ENSO. It is characterized by an anomalous warming in the central Pacific $\left(165^{\circ} \mathrm{E}-140^{\circ} \mathrm{W}\right)$ flanked by anomalous cooling at the eastern and western boundaries of the basin, thus generating an anomalous zonal SST gradient at the equator. This type of ENSO, i.e. El Niño Modoki, had been revealed and several observational studies reported contrasting effects on climate patterns worldwide (Ashok et al., 2007; Weng et al., 2007; Taschetto et al., 2009). At the present, few studies have analysed the impact of El Niño Modoki in monthly precipitation in South America.

However, the Pacific Ocean (PO) is not the only one that impact on precipitation over South America. Several authors analysed the teleconnections with other oceans of the tropical latitudes. Chan et al. (2008) found that the rainfall anomalies over South America are associated with the Indian Ocean (IO). A dipole in this ocean [Indian Ocean Dipole (IOD)] excites a dipolar pattern in monthly rainfall anomalies, located between the subtropical La Plata Basin and central Brazil. The rainfall is reduced (enhanced) over the latter (former) austral-spring, when IOD reaches its peak phase. Doyle and Barros (2002) signalled the importance of the preconditioning of the tropical Atlantic in the response of this basin to the remote El Niño influence. Moreover, they observed that increased rainfall over SESA is associated with a strengthened low-level Jet. Vera et al. (2006) showed that South American LowLevel Jet transports considerable moisture from the Amazon to Argentina, which contributes in the increase of precipitation. Barreiro (2009) found that the state of the equatorial Atlantic during El Niño years can modulate its influence on monthly rainfall over SESA during the summer. Muza et al. (2009) found that the South Atlantic SST dipole influences interannual variations of extreme precipitation events over southeastern Brazil. They showed that extreme wet and dry events in the continental portion of the SACZ are decoupled from extremes over the oceanic portion of the SACZ and there is no coherent dipole of extreme precipitation regimes between tropics and subtropics on interannual time scales.

Our main objective is to identify the regions at the tropical and subtropical oceans that are related with the extreme daily rainfall over Argentina. We analyse the temporal and spatial covariability between extreme daily rainfall in Argentina and the large-scales patterns of SST of the oceans southward of $17.5^{\circ} \mathrm{N}$, in the period 1962-2005. The article is organized as follows: Section 2 presents Data and methodology; Section 3 describes the Results and Section 4 highlights Conclusion.

\section{Data and methodology}

\subsection{Data}

The analysis is performed in the period 1962-2005 using two data sets:

(a) Monthly SST from the Kaplan SST V2 from the NCEP/NCAR. This data set includes monthly gridded measurements of global SST from 1870 to the present with a spatial resolution of $5^{\circ} \times 5^{\circ}$. The region under analysis comprises all of the oceans from $17.5^{\circ} \mathrm{N}-90^{\circ} \mathrm{S}$. Although the quality of this data set is very heterogeneous, the SST coverage is fairly 
complete during the period studied, and it is especially reliable after 1980 thanks to the inclusion of the available satellite observations.

(b) High quality daily rainfall for 35 surface stations from the National Weather Service of Argentina distributed throughout the country. Although more rain gauges exist in this region, only 35 stations were deemed suitable for the analysis as they passed quality control test (Penalba and Robledo, 2010), had long records, less than $10 \%$ missing data and a continuity in their records (Table I and Figure 1).

\subsection{Construction of rainfall indices}

By focusing on indices derived from raw daily data, we can overcome a major problem that is inherent in regional studies. The climate indices are very valuable to scientists for climate monitoring. Extreme events are infrequent meteorological phenomena that surpass a defined threshold and depend strongly on location (Das et al. 2003). Focusing in extreme conditions, Robledo and Penalba (2008) analysed different percentiles in

Table I. Number, name and location of the stations.

\begin{tabular}{|c|c|c|c|}
\hline No. & Name & Longitude & Latitude \\
\hline 1 & Ceres & -62.0 & -29.9 \\
\hline 2 & Sauce Viejo & -60.8 & -31.7 \\
\hline 3 & Nueve de Julio & -60.9 & -35.5 \\
\hline 4 & Junín & -60.9 & -34.6 \\
\hline 5 & Laboulaye & -63.4 & -34.1 \\
\hline 6 & Las Lomitas & -60.6 & -24.7 \\
\hline 7 & Malargüe & -69.6 & -35.1 \\
\hline 8 & Monte Caseros & -57.7 & -30.3 \\
\hline 9 & Mar del Plata & -57.6 & -37.9 \\
\hline 10 & Marcos Juarez & -62.2 & -32.7 \\
\hline 11 & Mendoza & -68.8 & -32.1 \\
\hline 12 & Neuquén & -68.1 & -39.0 \\
\hline 13 & Buenos Aires (OCBA) & -58.5 & -34.6 \\
\hline 14 & Paraná & -60.5 & -31.8 \\
\hline 15 & Pehuajó & -61.9 & -35.9 \\
\hline 16 & Pilar & -63.9 & -31.1 \\
\hline 17 & Posadas & -56.0 & -27.4 \\
\hline 18 & Río Gallegos & -69.3 & -51.6 \\
\hline 19 & Rosario & -60.8 & -32.9 \\
\hline 20 & Salta & -65.5 & -24.9 \\
\hline 21 & San Martín & -68.4 & -33.1 \\
\hline 22 & Santa Rosa & -64.3 & -36.6 \\
\hline 23 & Santiago del Estero & -64.3 & -27.8 \\
\hline 24 & Trelew & -65.3 & -43.2 \\
\hline 25 & Tucumán & -65.1 & -26.9 \\
\hline 26 & Villa Reynolds & -65.4 & -33.7 \\
\hline 27 & Villa María & -63.7 & -29.9 \\
\hline 28 & Tres Arroyos & -60.3 & -38.0 \\
\hline 29 & Azul & -59.9 & -36.1 \\
\hline 30 & Roque Saenz & -60.4 & -26.8 \\
\hline 31 & Concordia & -58.0 & -31.3 \\
\hline 32 & Corrientes & -58.8 & -27.5 \\
\hline 33 & Formosa & -58.2 & -26.2 \\
\hline 34 & Paso de los Libres & -57.2 & -29.7 \\
\hline 35 & Esquel & -71.2 & -42.9 \\
\hline
\end{tabular}

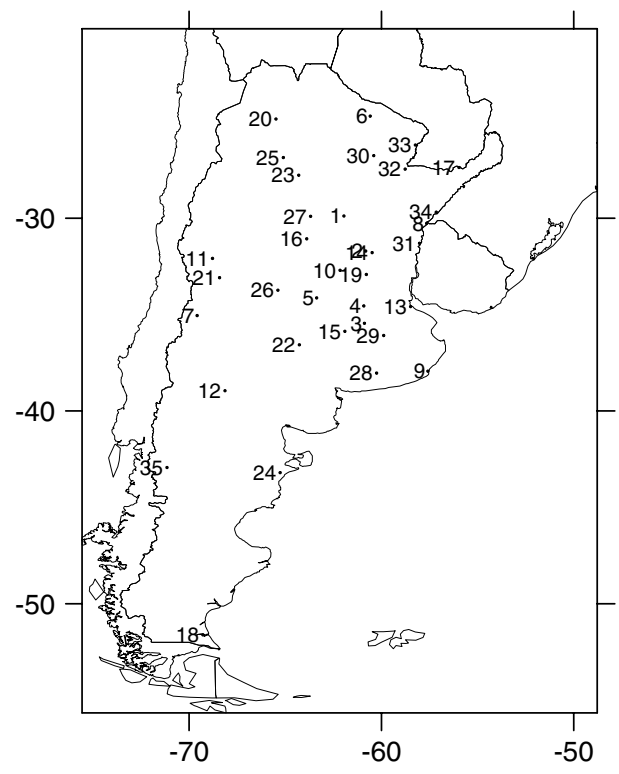

Figure 1. Location of stations over Argentina.

the region. Robledo and Penalba (2008) considered an extreme daily rainfall when the value is greater than a given threshold. This threshold is based on the 75th daily percentile which is determined empirically calculated on all the daily rainfalls for each meteorological station. This daily percentile series is clarified by smoothing the data using a 7 day running average. The climatological 75th daily percentile was considered in the period 1961-2000 as Robledo and Penalba (2008). According to these results, a relatively low threshold, 75th daily percentile, detects extreme conditions in the region (More details in Robledo and Penalba (2008)).

In this article, we are interesting in analysing the intensity of extreme daily rainfall. We compute the monthly mean of daily intensity of extreme rainfall index (hereafter the DIER index) as the quotient between the monthly accumulated extreme (AE) rainfall and the number of days with extreme precipitation events per month (PE),

$$
\operatorname{DIER}_{i, j}=\frac{\mathrm{AE}_{i, j}}{\mathrm{PE}_{i, j}}
$$

where $i$ represents months (i.e. from 1 to 12) and $j$ represents years (i.e. from 1962 to 2005). This index was calculated for each of the 35 meteorological stations.

For SST and DIER, all of the monthly time series span from December 1962 to November 2005. The monthly anomalies for both data sets are first computed by subtracting the 44 year monthly means from the original data. The analysis was performed from the monthly values of the index by calculating the quarterly average for the warm seasons as follows: summer (December, January and February, hereinafter DJF), autumn (March, April and May, hereinafter MAM) and spring (September, October and November, hereinafter SON). The linear trend of the extreme precipitation is not similar over all the region of study (Penalba and Robledo, 2010). To avoid the results being influenced by the presence of 
trends in time series, the analysis was carried out after linear trends were removed from the seasonal series (DIER and SST).

\subsection{Methodology}

Singular value decomposition (SVD) analyses were performed jointly on the DIER in Argentina and the SST from $17.5^{\circ} \mathrm{N}$ to $90^{\circ} \mathrm{S}$. SVD is a fundamental matrix operation that isolates linear combinations of variables within two fields that tend to be linearly related to another (Bretherton et al., 1992). In this sense, we used this methodology to explore the covariability between the two fields and to provide insight into the possible relations that could relate the extreme precipitation events with the ocean temperatures. The joint analysis allows us to objectively identify regions of the oceans that could be associated with extreme precipitation variability. A detailed description of the SVD method was given by Bretherton et al. (1992), Von Storch and Navarra (1995) and Venegas et al. (1997).

SST and DIER seasonal anomalies were standardized by dividing each time series by its seasonal standard deviation. This procedure enables comparisons among variables with different means and standard deviations and where the variability in one field might dominate the covariance structure between them. The temporal covariance matrix between normalized SST at each of the 799 grid points and DIER at each of the 35 meteorological stations were computed (see for instance Wallace et al., 1992).

For the spring, summer and autumn seasons, different SVD analyses were performed relating DIER with SST. In all cases, the first three modes were retained accounting for at least $54.4 \%$ of the squared covariance (SC) fraction. We used a Monte Carlo approach to determine the significance of the SST and DIER decompositions in modes of variability. A detailed description of the method is given in Section 2.4.

We constructed homogeneous correlation maps in order to show each mode centre of action distribution, scaled as correlation coefficients (Bretherton et al., 1992; Venegas et al., 1997). The homogeneous correlation maps are constructed as correlations between the time series of expansion coefficients (hereinafter SVD time series) of a given variable (in this case SST) and the grid point or station anomalies of the same variable. The homogeneous correlation maps show the spatial patterns, where the polarity and amplitude are represented by the corresponding expansion coefficients (Wallace et al., 1992). We also analysed the heterogeneous correlation maps which are constructed as correlation between the SVD time series of a given field and the grid point values or station values of the other field. It indicates how well the grid point values or station values of the second field can be specified from the knowledge of the expansion coefficient of the first.

In addition, the correlation maps provide a measure of the percentage of the variance explained locally by each mode, represented by the SC (Houghton and Tourre, 1992). All correlations exceeding \pm 0.26 are significant at the $95 \%$ confidence level based on a Student's $t$-test (Wilks, 1995). The correlation coefficient between both SVD time series was also considered as it provides a measure of how strongly the SST and DIER fields are related (Wallace et al., 1992).

\subsection{Statistical significance test}

To assess the statistical robustness of the results obtained from the SVD analysis, we performed a significance test using a Monte Carlo approach, as it is described in Wallace et al. (1992). We created a 'randomized' SST data set by scrambling the SST maps of the 44 years in the time domain, in order to break the chronological order of SST relative to DIER. Then, we performed an SVD analysis on each of the 250 scrambled data sets and analysed the SC. The 75th, 90th and 95th percentiles were calculated from the SC of the scrambled datasets. An SC value from the original datasets is statistically significant at the 75,90 or $95 \%$ level if it exceeds the corresponding percentile.

\subsection{Climate indices}

Several large-scale climate patterns have been synthesized in climate indices derived from SST anomalies, reducing complex space and time variability into simple measures. In this article, we analyse the Southern Tropical Atlantic Index (TSA) and El Niño 3.4 downloaded from the website of the Climate Prediction Center (CDC/NOAA) and the IOD index and El Niño Modoki index (EMI) downloaded from the website of the Japan Agency for Marine-Earth Science and Technology (More details of the indices in Table II). To analyse the possible mechanisms that relate the tropical SST and the extreme rainfall in Argentina, we explore the relationship of each mode derived from analysis of SVD with each climate indices. All correlations greater than $|0.25|$ are significant at the $95 \%$ significance with student's $t$-test (Wilks, 1995). All the indices were calculated in seasonal means. These indices were chosen because they represent regions of the oceans that show linkage to precipitation, through wave patterns as discussed in various works cited in the introduction. According to the phase in which the wave trains impact on SESA, the regional circulation is modified by altering the patterns of monthly precipitation.

\section{Results}

\subsection{Preliminary analysis}

Initially, we explored the relation between SST at the studied region and the DIER index in Argentina. For each season, we calculated the simple correlation coefficient between the DIER at each station and normalized SST at each point of the 799 grid points. All correlations exceeding \pm 0.29 are significant at the $95 \%$ confidence level based on a Student's $t$-test. The stations with higher 
Table II. Climate indices derived from SST anomalies.

\begin{tabular}{lll}
\hline Index & Definition & Source author \\
\hline Southern Tropical Atlantic Index (TSA) & $\begin{array}{l}\text { Anomalies of the monthly average of SST in the region } \\
\text { considered to be between Ecuador and } 20^{\circ} \mathrm{S} \text { and } 10^{\circ} \mathrm{E} 30^{\circ} \mathrm{W}\end{array}$ & Enfield et al. (1999) \\
The intensity of the IOD is represented by gradient anomaly of & Saji et al. (1999) \\
SST between the west equatorial Indian Ocean $\left(50^{\circ} \mathrm{E}-70^{\circ} \mathrm{E}\right.$ & \\
& $\begin{array}{l}\left.\text { and } 10^{\circ} \mathrm{S}-10^{\circ} \mathrm{N}\right) \text { and south eastern } \\
\text { Niño } 3.4\end{array}$ & $\begin{array}{l}\mathrm{SST} \text { anomaly in the central Pacific region whose limits are } \\
5^{\circ} \mathrm{N}-5^{\circ} \mathrm{S} \text { and } 170^{\circ} \mathrm{W}-120^{\circ} \mathrm{W}\end{array}$ \\
& $\begin{array}{l}\text { Difference of SST anomaly between the region A corresponds } \\
\text { to the box bounded by } 165^{\circ} \mathrm{E}-140^{\circ} \mathrm{W}, 10^{\circ} \mathrm{S}-10^{\circ} \mathrm{N} \text { and the }\end{array}$ & Ashok et al. (2007) \\
& region B bounded by $110^{\circ} \mathrm{W}$ & \\
\hline
\end{tabular}
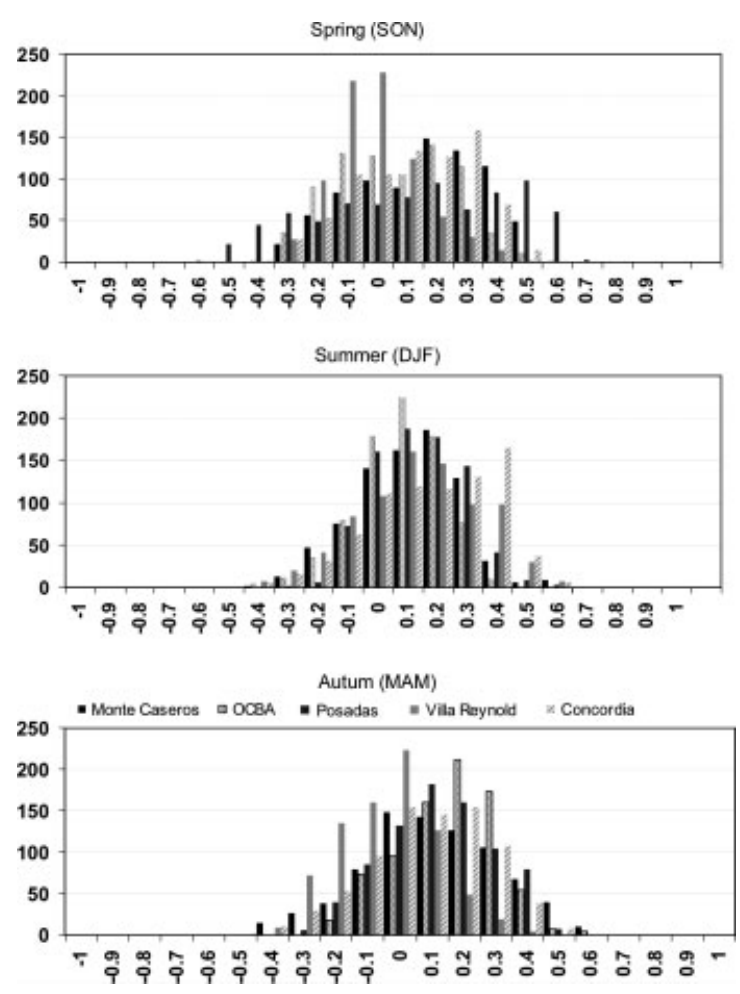

Figure 2. Absolute frequency distribution of simple correlation coefficient between the DIER at different stations and normalized SST at each point of the 799 grid points for spring (SON), summer (DJF) and autumn (MAM).

correlations with SST have been selected: Monte Caseros, OCBA, Posadas, Villa Reynolds and Concordia. The absolute frequency distribution of simple correlation for each station is shown in Figure 2.

For spring, Posadas, located in northeastern Argentina, presents positive (negative) and significative correlation with 309 (127) grid points of the SST. The location of the positive (negative) grid points association is concentrated in three (one) specific regions: east tropical PO, west IO and tropical AO (Southwest PO).

The strongest ENSO-monthly rainfall relationship in Argentina is observed in the northeastern part of the country. In terms of extreme daily rainfall, Posadas shows 61 correlation coefficients greater than 0.6 with grid points located in the Pacific ENSO domain.
Monte Caseros and Concordia, located in centraleastern Argentina, present positive and significant correlation with 300 and 246 grid points of the SST, respectively. These points correspond to east tropical Pacific, west Indian and tropical and subtropical AO. To the south, at OCBA station, the positive relationship decreases (164 points). Villa Reynolds, located in central-western Argentina close to the Andes, is the station with less positive significant correlation coefficients (48). However, these points are concentrated in south west Pacific.

In summer, DIER at Concordia presents positive (negative) and significant correlation with 349 (20) grid points of the SST at the central Pacific, IO and the tropical and subtropical AO. Villa Reynolds presents positive (negative) significant correlations with 235 (27) SST field grid points.

In autumn, DIER at Monte Caseros presents positive (negative) and significant correlation with 223 (8) grid points of the SST at the central PO and tropical AO. Buenos Aires presents positive (negative) significant correlations with 240 (13) SST field grid points at the central PO and the IO. Villa Reynolds, located in centralwestern Argentina, is the station with more negative significant correlation coefficients with 81 grid points of the SST at the tropical Atlantic and the southwest PO.

These results show evidence on the connection between SST and extreme precipitation in Argentina. The results suggest that there exist different regions of the oceans, alternative to the ENSO region, that are linked to DIER. These results encouraged us to try to identify and isolate the modes of the covariability between the two fields through the SVD methodology.

\subsection{Monte Carlo results}

The squared covariance fractions (SCF) explained by each mode and the correlation coefficient $(\mathrm{R})$ between the expansions coefficients of both variables as indicators of the strength of the coupling are displayed in Table III. The three first modes were retained and account for at least $50 \%$ of the SCF for each season.

According to the results of the Monte Carlo test, the first and second modes of the SVD for spring are found to be highly significant (more than 95\% level) (Table IV). 
Table III. Summer, autumn and spring SCF explained by the first three modes and the correlation coefficient $(\mathrm{R})$ between the expansions coefficients of both variables.

\begin{tabular}{|c|c|c|c|c|c|c|}
\hline & \multicolumn{2}{|c|}{ Summer (DJF) } & \multicolumn{2}{|c|}{ Autumn (MAM) } & \multicolumn{2}{|c|}{ Spring (SON) } \\
\hline & $\mathrm{SCF}(\%)$ & $R$ & $\operatorname{SCF}(\%)$ & $R$ & $\mathrm{SCF}(\%)$ & $R$ \\
\hline SVD 1 & 34.3 & 0.63 & 34.5 & 0.71 & 46.7 & 0.78 \\
\hline SVD 2 & 11.3 & 0.72 & 11.5 & 0.68 & 17.1 & 0.75 \\
\hline SVD 3 & 9.8 & 0.70 & 8.4 & 0.67 & 6.0 & 0.77 \\
\hline
\end{tabular}

All correlation coefficients are significant at $95 \%$ with the Student's $t$-test.

Table IV. SC accounted by the first three SVD modes from the observed SST and DIER datasets (Observation) and from the 250 scrambled datasets.

\begin{tabular}{lrrrr}
\hline & & \multicolumn{3}{c}{ Mode } \\
\cline { 3 - 5 } & & 1 & 2 & 3 \\
\hline SON & & & & \\
Percentiles of Scrambled data & 95 & 19.72 & 9.20 & 5.76 \\
& 90 & 18.14 & 8.59 & 5.59 \\
& 75 & 15.51 & 7.49 & 5.01 \\
Observation & & $\mathbf{2 7 . 8 9}$ & $\mathbf{1 1 . 0 0}$ & 3.85 \\
MAM & & & & \\
Percentiles of Scrambled data & 95 & 17.53 & 8.57 & 5.76 \\
& 90 & 15.57 & 8.28 & 5.45 \\
& 75 & 13.20 & 7.44 & 5.05 \\
Observation & & $\mathbf{1 6 . 2 9}$ & 5.41 & 3.97 \\
DJF & & & & \\
Percentiles of Scrambled data & 95 & 20.19 & 8.39 & 5.64 \\
& 90 & 17.66 & 7.93 & 5.28 \\
Observation & 75 & 15.16 & 7.15 & 4.83 \\
& & $\mathbf{1 7 . 0 3}$ & 5.61 & 4.84 \\
\hline
\end{tabular}

Spring (SON), Autumn (MAM) and Summer (DJF). Percentiles 75th, 90th and 95th calculated from the SC of the scrambled data sets. All the SCs are normalized by dividing by the number of grid points of each variable $(35 \times 799)$. The bold values are significant at 75 th, 90 th or 95th agreement if the observations exceed percentilies of scrambled data.

The third mode is not significant, for any of the three levels of significance. For summer and autumn, the first mode is significant at the $90 \%$ level, while the second and third modes are not significant (Table IV). Although some modes are not significant through Monte Carlo analysis, we decided to retain them at this point of the analysis.

\subsection{Covariability of SST and DIER}

\subsubsection{Spring}

The three leading SVD modes of the coupled SST and DIER variations account for $69 \%$ of the total squared covariance (TSC) (Table III). The first mode accounts for $47 \%$ of the TSC and resembles a typical El Niño phenomenon pattern (Figure 3, second column). This mode presents warm SST across the tropical PO and IO associated with high DIER in central and northeastern
Table V. Correlation between times series of the SVD modes of the SST and the climate indices.

\begin{tabular}{lrrr}
\hline & Mode 1 & Mode 2 & Mode 3 \\
\hline SON & & & \\
Niño 3.4 & 0.90 & 0.16 & -0.10 \\
TSA & 0.16 & -0.71 & 0.25 \\
IOD & 0.77 & 0.08 & 0.27 \\
MODOKI & 0.56 & 0.30 & -0.38 \\
MAM & & & \\
Niño3.4 & 0.88 & -0.11 & 0.00 \\
TSA & -0.02 & 0.68 & -0.03 \\
IOD & -0.13 & -0.04 & 0.09 \\
MODOKI & 0.14 & 0.29 & -0.02 \\
DJF & & & \\
Niño3.4 & 0.69 & -0.20 & 0.37 \\
TSA & 0.36 & 0.34 & -0.02 \\
IOD & -0.05 & 0.22 & -0.02 \\
MODOKI & 0.33 & -0.30 & 0.60 \\
\hline
\end{tabular}

Spring (SON), Autumn (MAM) and Summer (DJF). Correlations exceeding $|0.26|$ are significant at the $95 \%$ according a Student's $t$-test.

Argentina (Figure 3, first column). This is consistent with results of Vera et al. (2004), where the impact on monthly rainfall in SESA during spring is higher during an El Niño episode where the sign of the SST anomaly in the equatorial PO is opposite to the anomaly of south central Pacific. In terms of variance explained (calculated as the square of the correlation coefficients in Figure 3, first column), the SST field explains more than $30 \%$ of the variability of the extreme rainfall at some stations in northeastern Argentina, for example, Posadas (36\%) and Paso de los Libres (34\%). The wavelet analysis of the SVD time series of SST shows a typical 4 year cycle, particularly during the 1970s and 1980s (Figure 3, third column). Table $\mathrm{V}$ shows the correlation between the SVD time series of SST for each mode of spring and the climate indices. The first mode of spring has significant and positive correlation with the Niño 3.4 index, Niño Modoki and IOD which are 0.90, 0.56 and 0.77 , respectively, all significant at $1 \%$ (Table V, SON).

The second mode presents a strong cooling SST in the tropical and subtropical AO and the northeastern IO, near the Indonesian Sea (Figure 3, second column) and it is associated with a high DIER in central and western Argentina (Figure 3, first column). The SST field of the second mode explains more than $20 \%$ of the variability of the extreme rainfall at some stations in central and western Argentina, for example Marcos Juarez (21\%) and Mar del Plata (14\%). This mode has a $17 \%$ TSC and shows two different cycles of variability, the first with an 8 year period and the second with a 15 year period (Figure 3, third column). The correlation between the second mode SVD time series of SST anomaly and TSA for spring is negative and significant $(-0.71)$. However, the second mode also has a significant positive correlation, although weak, with little Niño Modoki (0.3). 


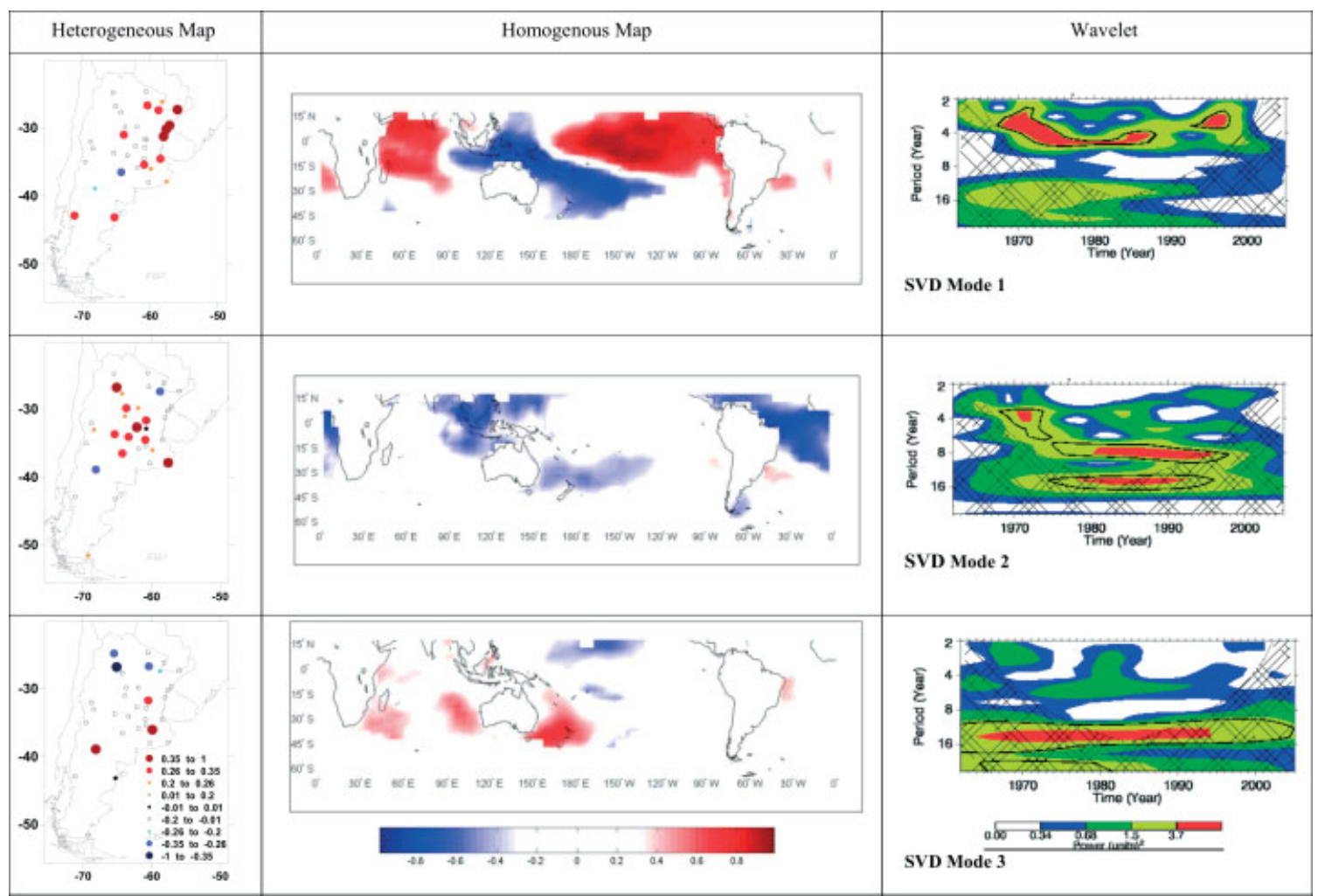

Figure 3. Spring (left) Heterogeneous correlation map between the SVD time series of SST and the DIER anomalies over Argentina. Correlations exceeding $|0.26|$ are significant at the 95\% confidence level. Red (blue) dots are positives (negative) values (Middle). Homogeneous correlation map between the SVD time series of SST and the SST grid point anomalies. Areas where values are statistically significant at $95 \%$ are shaded. (Right) Wavelet analysis of the SST time series of expansion coefficient for each mode (third column). This figure is available in colour online at wileyonlinelibrary.com/journal/joc

The third mode presents a low DIER in northern Argentina associated with warm conditions of the SST close to New Zealand's and shows a 12 year cycle (Figure 3, third column). The SST field of the third mode explains around $10 \%$ of the variability of the extreme rainfall at some stations in northern Argentina, for example Tucuman (17\%). The SVD time series of SST in the third mode has a positive and significant correlation with the IOD index for spring (0.27), and negative and significant with El Niño Modoki $(-0.38)$.

\subsubsection{Summer}

The three leading SVD modes of the coupled SST and DIER variations account for $55 \%$ of the TSC (Table III). The first mode exhibits a higher DIER than normal in central and eastern Argentina that is associated with warm SST in the equatorial $\mathrm{PO}$ and the equatorial IO (Figure 4). The correlations between the first mode of the SVD time series of SST and the indices of Niño 3.4 and Niño Modoki are positive and significant at $1 \%$ (0.69 and 0.33 , respectively Table V, DJF). The SST field of the first mode explains around $15 \%$ of the variability of the extreme rainfall at some stations in northeastern Argentina, for example, Roque Saenz (14\%) and Concordia (16\%), and around $10 \%$ in central-eastern Argentina, for example, Sauce Viejo (10\%). This mode accounts for $34.3 \%$ of the TSC and can be related to a typical El Niño phenomenon, showing 4 year cycles during the 1970s and 1980s (Figure 4). This mode, as well as its temporal behaviour, is similar to the first mode of spring.

The second mode shows warm SST in the tropical and subtropical $\mathrm{AO}$ and in the southwestern $\mathrm{PO}$, near the eastern coast of Australia (Figure 4). This mode accounts for $11.3 \%$ of the TSC. This pattern is associated with a low DIER without spatial coherence and shows 14 year cycles during the 1980s (Figure 4). The SST field of the second mode explains around $10 \%$ of the variability of the extreme rainfall at some stations in eastern Argentina, for example, Concordia (7\%) and Paraná (13\%), and more than $14 \%$ at Esquel, in southwestern Argentina. The correlation between the second mode of the SVD time series of SST for summer and TSA is positive and significant $(0.34$, Table $\mathrm{V})$, and negative and significant with El Niño Modoki (-0.30) (Table V). Ambrizzi et al. (2005) found that during the summer, the combination of sometimes called Atlantic dipole [warm (cold) anomaly in the northern (southern) tropical Atlantic (South)] and an El Niño event is a decrease of precipitation in northern SESA $\left(20^{\circ} \mathrm{S}\right)$. In contrast with a weak El Niño and negative phase of the Atlantic dipole decreased precipitation moves to the centre of SESA $\left(30^{\circ} \mathrm{S}\right)$. Ambrizzi et al. (2005) suggested that during weak El Niño episodes, the anomalies SST of the Atlantic control the circulation patterns and precipitation in northeastern 


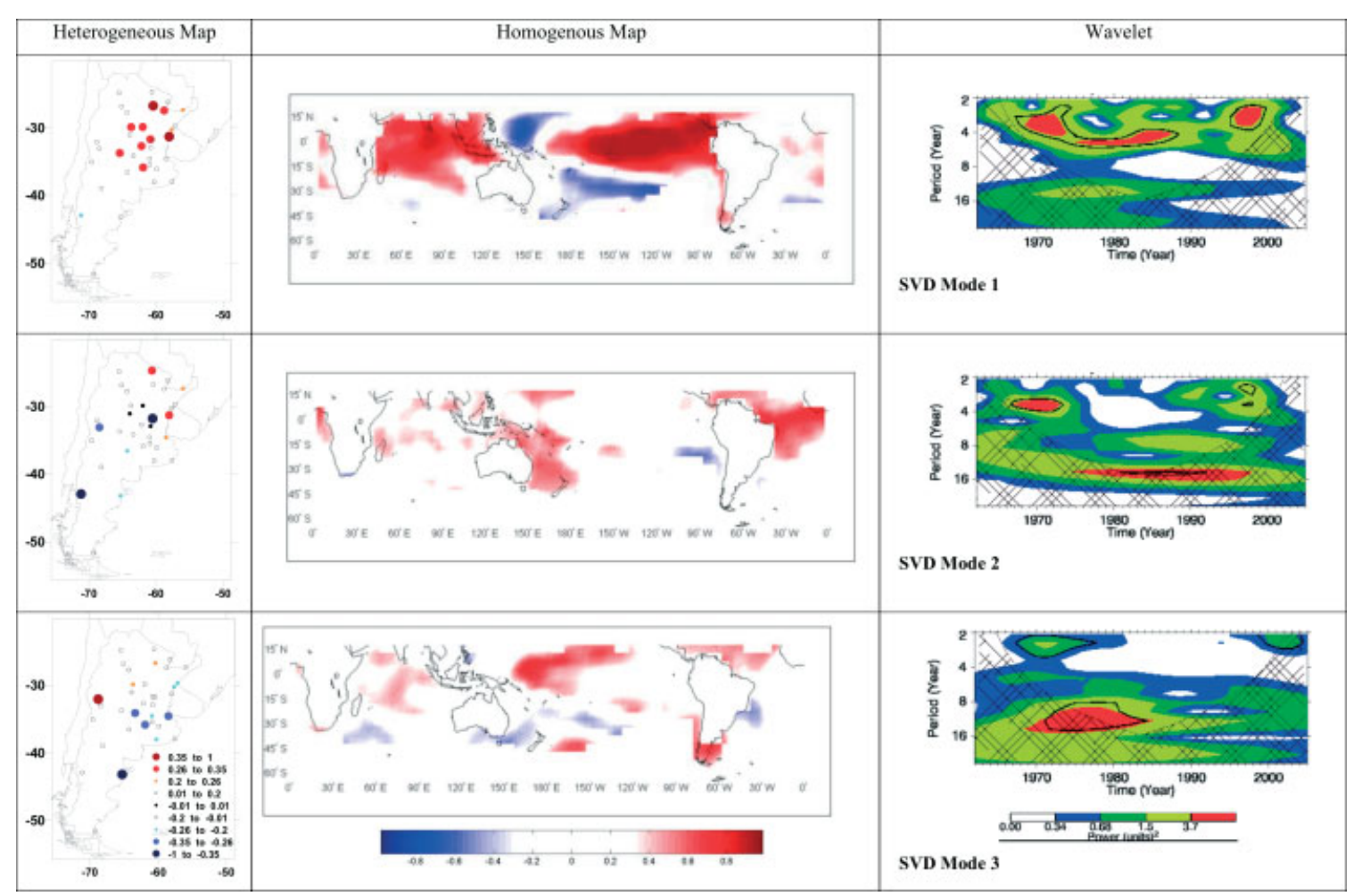

Figure 4. Summer (left) Heterogeneous correlation map between the SVD time series of SST and the DIER anomalies over Argentina. Correlations exceeding |0.26| are significant at the 95\% confidence level. Red (blue) dots are positives (negative) values. (Middle) Homogeneous correlation map between the SVD time series of SST and the SST grid point anomalies. Areas where values are statistically significant at $95 \%$ are shaded. (Right) Wavelet analysis of the SST time series of expansion coefficient for each mode (third column). This figure is available in colour online at wileyonlinelibrary.com/journal/joc

Brazil and SESA. Robertson and Mechoso (2000) and Muza et al. (2009) also identified a relation of the SST anomalies in the tropical and subtropical Atlantic and rainfall in southeastern Brazil.

The third mode accounts for $9.8 \%$ of the TSC. It shows a strong spatial coherence pattern of low DIER in central and eastern Argentina and is coupled with warm SST in the AO and western PO between the equator and $15^{\circ} \mathrm{N}$ (Figure 4). The SST field of the third mode explains $10 \%$ of the variability of the extreme rainfall at some stations in the central part of Argentina, for example, at Laboulaye (11\%), Mendoza (13\%) and Tres Arroyos (7\%). For this mode, a small regional cooling of SST at $20^{\circ} \mathrm{S}-30^{\circ} \mathrm{W}$ in the south west tropical AO, could be associated with the low DIER (Figure 4). The correlation of the third SVD time series of SST show positive and significant correlation with Niño 3.4 (0.37) (Table V). However, the higher positive correlation with the El Niño Modoki (0.60) is consistent with the spatial structure of SST anomaly which is similar to that associated with the El Niño Modoki (Ashok et al., 2007).

\subsubsection{Autumn}

The three leading SVD modes of the coupled SST and DIER variations account for $54 \%$ of the TSC (Table III). Like situations in summer and spring, the first mode of autumn presents 4 year cycles and evidences a typical El Niño phenomenon with a high DIER in central and northeastern Argentina (Figure 5), accounting for $34.5 \%$ of the TSC. The SST field of the first mode explains around $18 \%$ of the variability of the extreme rainfall at Monte Caseros (20\%), in eastern Argentina. In the central part of Argentina, the SST field explains around $10 \%$ of the DIER. However, its signal seems to have become more evident during the 1980s and 1990s. These results are consistent with the positive and significant correlation between the first mode of the SVD time series of SST and the Niño 3.4 (0.88) (Table V). Correlations are not significant with the IOD and El Niño Modoki.

The second mode accounts for $11.5 \%$ of the TSC and presents a similar pattern to the second mode of SST for summer (warm in the subtropical AO), but the DIER is opposite with high values in the central east (Figure 5). The SST field of the second mode explains around $10 \%$ of the variability of the extreme rainfall in central Argentina, for example at Buenos Aires (11\%) and Nueve de Julio (7\%). At Salta, in the northwest part of Argentina the SST field explains $10 \%$ of the DIER. However, the second mode of autumn does not present a clear interdecadal variability. The correlations with the climate indices also support the regions of the oceans identified by this second mode. The correlations are 0.68 for TSA and 0.29 for the Niño Modoki, both positive and significant. However, the correlations with Niño 3.4 and IOD are not significant (Table V).

The third mode accounts for $8.4 \%$ and shows a low DIER in central and northeastern Argentina associated 


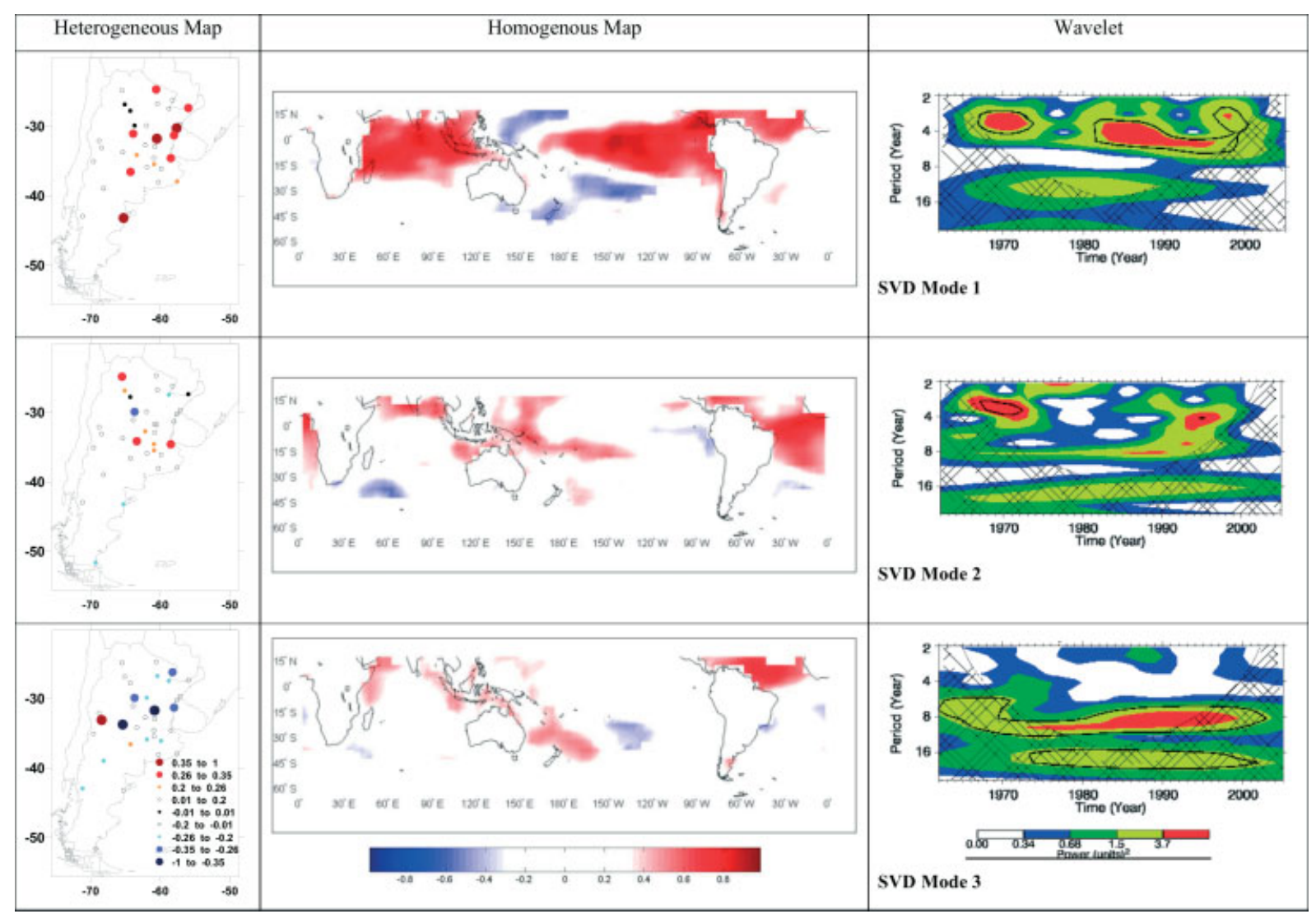

Figure 5. Autumn (left) Heterogeneous correlation map between the SVD time series of SST and the DIER anomalies over Argentina. Correlations exceeding $|0.26|$ are significant at the 95\% confidence level. Red (blue) dots are positives (negative) values. (Middle) Homogeneous correlation map between the SVD time series of SST and the SST grid point anomalies. Areas where values are statistically significant at $95 \%$ are shaded. (Right) Wavelet analysis of the SST time series of expansion coefficient for each mode (third column). This figure is available in colour online at wileyonlinelibrary.com/journal/joc

with warm SST in the tropical AO and the southwestern PO, north of New Zealand; this mode shows 8 year cycles of temporal variability (Figure 5 ) throughout all the records. The SST field of the third mode explains $12 \%$ of the variability of the extreme rainfall in central-western Argentina. This mode does not present significant correlations with any of the climatic indices. The three SVD modes present a warming in the tropical AO, Doyle and Barros (2002) and Barreiro (2009) signalled the importance of the preconditioning of the tropical Atlantic in the response of this basin to the remote El Niño influence. In addition, the variability of precipitation anomaly dipole SESA-SACZ is related to SST anomalies in the Tropical South AO. In particular, positive phases of the dipole pattern corresponds to positive anomalies of precipitation over SESA and negative on SACZ, associated with warm SST anomalies in the western tropical Atlantic (Doyle and Barros, 2002).

It is important to mention that the first SVD mode identified the equatorial PO explaining high and significant variability in all seasons. Therefore, other regions of the oceans identified by the remaining modes, with less explained variance, will be 'hidden' or imperceptible. These remaining modes are the ones that will identify ocean regions, alternative to ENSO, that are linked to heavy precipitation in Argentina.
The analysis presented in this article was done with an index that measures extreme precipitation (DIER). Due to the nature of extreme precipitation and the characteristics of the links investigated, the demand of statistical significance in the modes could become very rigorous in terms of the analysis of the SSTs-extreme precipitation relationship.

On the other hand, in this article, we analyse Argentina as a whole, where coexist different precipitation regimes. So, small explained variances can be non-disregardable, in a physical sense. If we take into account these considerations, it is important to consider specific SST regions identified by the modes that were not significant from the Monte Carlo test, but that demonstrated to be relevant when analysing the simple correlations in the preliminary results and the association between observed time series. Because the regions identified by the modes, proved to be of interest, we consider important to retain the first three modes for a future analysis of the possible cause-effect relation from the dynamic point of view.

\section{Conclusion}

We have explored the covariability between SSTs for all the oceans from $17.5^{\circ} \mathrm{N}$ to $90^{\circ} \mathrm{S}$ and the DIER in 
Argentina, in the period 1962-2005. This analysis was performed for three austral seasons (spring, summer and autumn), using SVD. The three leading SVD modes of the coupled SST and DIER variations account for around $55 \%$ for summer and autumn and $70 \%$ for spring of the total squared covariance. We have used wavelet methodology to analyse localized variations of power within the time series for each seasonal mode.

The large percentage of the covariance explained by the first SVD mode, for all seasons, suggests a fair degree of predictability between the DIER and SST. Spring registers the highest SCF, $45 \%$, whereas summer and autumn register $34 \%$. These SST patterns have 4 year temporal cycles and relate to the ENSO phenomena with an enhanced DIER in central and eastern Argentina.

In the second SVD mode, spring has the highest SCF, $17 \%$, whereas summer and autumn register $11 \%$. For autumn and summer the tropical and subtropical Atlantic present covariability with the DIER in central Argentina. Apart from the AO, spring also presents significant covariability with the Indonesian Sea. This mode shows a decadal variability with two sub-periods: 8 years and 12 years.

In the third SVD mode of spring and summer the SCF are 10 and $6 \%$, respectively; the IO presents covariability with the DIER in the northern and eastern portion of Argentina, respectively. This mode shows a significant period of variability, around 14 years. In autumn, the third mode presents a significant correlation of the tropical $\mathrm{AO}$ and extreme rainfall in the centre and eastern Argentina, with significant period of 14 years.

In this work, we identified different SST regions of the oceans related with the DIER in Argentina: the tropical and subtropical AO and the Indonesian Sea, in addition to areas of the IO. Moreover, the temporal variability of each of these SST regions was detected and recognized as a possible large-scale forcing of extreme rainfall variability over the studied region.

The significant results of the correlations with various climate indices support the SST regions identified that show a relationship with DIER in Argentina. The first mode of SVD analysis for each season is associated with the ENSO. In addition, the central tropical Pacific was also identified as a source of DIER decadal variability in the first mode of the seasonal analysis. It was found that the IOD signal appears significantly related to DIER only in spring with positive anomalies in central and northeastern Argentina. El Niño Modoki was also identified as a source of variability DIER. The second mode of autumn and spring, and the third of summer, have a spatial structure of SST anomaly similar to El Niño Modoki described by Ashok et al. (2007).

Therefore, in order to analyse potential mechanisms of how the SSTs may influence the extreme rainfall events over Argentina, additional analysis is needed. An integral dynamic analysis is required, considering the different physical scales involved: planetary scale, regional circulation over South America and a meso scale systems over Argentina. The planetary features influence the regional circulation over South America, could generate different weather types that will modify the intensity of the extreme rainfall. Another analysis is to evaluate the contribution of each individual basin and the examination of the dynamic linkage between its variability and extreme rainfall in the region under study. Each of these approaches will be considered in future researches to understand the physical mechanisms leading to extreme daily precipitation events in Argentina.

\section{Acknowledgements}

We thank anonymous referees for their valuable comments and critical reading of the manuscript. We are grateful to the University of Buenos Aires UBA 20020100100789 and UBA 20020100200165 , CLARIS La Plata Basin Project (European Commission Project) and PIP 11220100100227 CONICET for their generous support for this research project. National Weather Service of Argentina provided the data set used in this work.

\section{References}

Aceituno P. 1988. On the functioning of the Southern Oscillation in the South American sector. Part I: Surface climate. Monthly Weather Review 116: 505-524.

Ambrizzi T, De Souza EB, Pulwarty RS. 2005. The Hadley and Walker regional circulations and associated ENSO impacts on South American seasonal rainfall. In Hadley Circulation: Present, Past and Future, Diaz HF, Bradley RS (eds). Kluwer Academic Press: Dordrecht, 203-235.

Antico P. 2008. Relationships between autumn precipitation anomalies in southeastern South America and El Niño event classification. International Journal of Climatology 29: 719-727, DOI: 10.1002/joc. 1734 .

Ashok K, Behera SK, Rao SA, Weng H, Yamagata T. 2007. El Niño Modoki and its possible teleconnection. Journal of Geophysical Research 112: C11007, DOI: 10.1029/2006JC003798.

Barreiro M. 2009. Influence of ENSO and the South Atlantic Ocean on climate predictability over Southeastern South America. Climate Dynamic 35: 1493-1508, DOI: 10.1007/s00382-009-0666-9.

Barros V, Silvestri G. 2002. On the relation between sea surface temperature at the subtropical south-central pacific and precipitation in southeastern South America. Journal of Climate 15: 251-267.

Bretherton CS, Smith C, Wallace JM. 1992. An intercomparison of methods for finding coupled patterns in climate data. Journal of Climate 5: 541-560.

Boulanger JP, Leloup J, Penalba OC, Rusticucci MM, Lafon F, Vargas WM. 2005. Observed precipitation in the Paraná-Plata hydrological basin: long-term trends, extreme conditions and ENSO teleconnections. Climate Dynamic 24: 393-413, DOI: 10.1007/s00382-004-0514-x.

Castañeda M, Barros V. 1994. Las tendencias de la precipitación en el cono sur de América al este de los Andes. Meteorológica 19: 23-32.

Chan SC, Behera SK, Yamagata T. 2008. Indian Ocean Dipole influence on South American rainfall. Geophysical Research Letters 35: L14S12, DOI: 10.1029/2008GL034204.

Das HP, Adamenko TI, Anaman KA, Gommes RG, Johnson G. 2003. Agrometeorology-related to extreme events. Technical Note No. 201. WMO 943: 137.

Diaz AF, Studzinski CD, Mechoso CR. 1998. Relationships between precipitation anomalies in Uruguay and Southern Brazil and sea surface temperature in the Pacific and Atlantic Oceans. Journal of Climate 11: 251-271.

Doyle ME, Barros V. 2002. Midsummer low-level circulation and precipitation in subtropical South America and related sea surface temperature anomalies in the South Atlantic. Journal of Climate 15: 3394-3410.

Enfield DB, Mestas AM, Mayer DA, Cid-Serrano L. 1999. How ubiquitous is the dipole relationship in tropical Atlantic sea surface temperatures? Journal of Geophysical Research 104: 7841-7848. 
García NO, Vargas WM. 1998. Análisis de la variabilidad climática en la Cuenca del Río de la Plata, a través de sus caudales y búsqueda de precursores de extremos hídricos. Reporte Final del Proyecto de la Comunidad Europea "Assessing the impact of future climatic change on the water resources and the hydrology of the Río de la Plata Basin, Argentina. Contract N ${ }^{\circ}$ ARG/B7-3011/94/25.

Grimm AM, Barros VR, Doyle ME. 2000. Climate variability in southern South America associated with El Niño and La Niña events. Journal of Climate 13: 35-58.

Grimm A, Tedeschi R. 2009. ENSO and extreme rainfall events in South America. Journal of Climate 22: 1589-1609.

Haylock MR, Peterson T, Abreu de Sousa JR, Alves LM, Ambrizzi T, Anunciação YMT, Baez J, Barbosa de Brito JI, Barros VR, Berlato MA, Bidegain M, Coronel G, Corradi V, Garcia VJ, Grimm AM Jaildo dos Anjos R, Karoly D, Marengo JA, Marino MB, Meira PR, Miranda GC, Molion L, Moncunill Nechet D, Ontaneda G, Quintana J, Ramirez E, Rebello E, Rusticucci M, Santos JL, Trebejo I, Vincent L. 2006. Trends in total and extreme South American precipitation 1960-2000 and links with sea surface temperature. Journal of Climate 19: 1490-1512.

Houghton JT, Jenkins JG, Ephraums JJ. 1990. Climate Change: The IPCC Scientific Assessment, Cambridge University Press: 366.

Houghton JT, Tourre Y. 1992. Characteristics of low-frequency sea surface temperature fluctuations in the tropical Atlantic. Journal of Climate 5: 765-771.

Karl T, Kukla G, Gavin J. 1984. Decreasing diurnal temperature range in the United States and Canada. Journal of Climate and Applied Meteorology 23: 1489-1504.

Kidson JW. 1999. Principal modes of Southern Hemisphere low frequency variability obtained from NCEP-NCAR reanalyses. Journal of Climate 12: 2808-2830.

Krepper CM, Scian BV, Pierini JO. 1989. Time and space variability of rainfall in central-east Argentina. Journal of Climate 2: 39-47.

Mearns L, Katz R, Schneider S. 1984. Extreme high-temperature events: changes in their probabilities with changes in mean temperature. Journal of Climate and Applied Meteorology 23: $1601-1613$.

Minetti JL, Vargas WM. 1997. Trends and jumps in the annual precipitation in South America, south of the $15^{\circ} \mathrm{S}$. Atmósfera 11: 205-221.

Minetti JL, Vargas WM, Poblete AG, Acuna LR, Casagrande G. 2003 Non-linear trends and low frequency oscillations in annual precipitation over Argentina and Chile, 1931-1999. Atmósfera 16: $119-135$

Montecinos A, Díaz A, Aceituno P. 2000. Seasonal diagnostic and predictability of rainfall in subtropical South America based on tropical Pacific SST. Journal of Climate 13: 746-758.

Muza MN, Carvalho LMV, Jones C, Liebmann B. 2009. Intraseasonal and Interannual Variability of Extreme Dry and Wet Events over Southeastern South America and the Subtropical Atlantic during Austral Summer. Journal of Climate 22: 1682-1699.
Penalba OC, Robledo FA. 2010. Spatial and temporal variability of the frequency of extreme daily rainfall regime in the La Plata Basin during the 20th century. Climatic Change 98: 531-550, DOI: 10.1007/s10584-009-9744-6.

Penalba OC, Vargas WM. 1996. Climatology of monthly and annual rainfall in Buenos Aires, Argentina. Meteorological Applications 3: 275-282.

Penalba OC, Vargas WM. 2004. Interdecadal and Interannual variations of annual and extreme precipitation over centralnortheastern Argentina. International Journal of Climatology 24(12): $1565-1580$

Penalba OC, Vargas WM. 2008. Variability of low monthly rainfall in La Plata Basin. Meteorological Applications 15: 313-323, DOI: 10.1002/met.68.

Robertson AW, Mechoso CR. 2000. Interannual and interdecadal variability of the South Atlantic convergence zone. Monthly Weather Review 128: 2947-2957.

Robledo FA, Penalba OC. 2008. Análisis estacional de la frecuencia diaria y la intensidad de extremos de sobre el sudeste de Sudamérica precipitación. Meteorológica 32: 31-40.

Rogers JC. 1988. Precipitation variability over the Caribbean and tropical Americas associated with the Southern Oscillation. Journal of Climate 1: 172-182.

Ropelewski CF, Halpert MS. 1987. Global and regional scale precipitation patterns associated with the El Niño/Southern Oscillation. Monthly Weather Review 115: 1606-1626.

Rusticucci MM, Penalba OC. 2000. Interdecadal changes in precipitation seasonal cycle over South America. Relationship with surface temperature. Climate Research 16: 1-15.

Saji NH, Goswami BN, Vinayachandran PN, Yamagata T. 1999. A dipole mode in the tropical Indian Ocean. Nature 401: 360-363.

Taschetto AS, England MH. 2009. El Niño Modoki impacts on Australian rainfall. Journal of Climate 22: 3167-3174.

Venegas SA, Mysak LA, Straub DN. 1997. Atmosphere-ocean coupled variability in the South Atlantic. Journal of Climate 10: 2904-2920.

Vera C, Higgins W, Amador J, Ambrizzi T, Garreaud R, Gochis D, Gutzler D, Lettenmaier D, Marengo J, Mechoso CR, NoguesPaegle J, Silva Dias PL, Zhang C. 2006. A unified view of the American monsoon systems. Journal of Climate 19: 4977-5000.

Vera C, Silvestri G, Barros V, Carril A. 2004. Differences in El Niño response over the Southern Hemisphere. Journal of Climate 17: $1741-1753$.

Von Storch H, Navarra A. 1995. Analyses of Climate Variability-Applications of Statistical Techniques, Springer: 334.

Wallace JM, Smith C, Bretherton CS. 1992. Singular value decomposition of wintertime sea-surface temperature and $500 \mathrm{mb}$ height anomalies. Journal of Climate 5: 561-576.

Weng H, Ashok K, Behera SK, Rao SA, Yamagata T. 2007. Impacts of recent El Niño Modoki on dry/wet conditions in the Pacific rim during boreal summer. Climate Dynamics 29: 113-129.

Wilks D. 1995. Statistical Methods in the Atmospheric Sciences, An introduction, Academic Press: San Diego. 